\title{
A tradução da política de avaliação pelos programas de pós-graduação em educação no Brasil
}

\author{
The Translation of the Evaluation Policy by the Brazil's Postgraduate \\ Programmes in Education
}

\author{
Regina Célia Linhares Hostins ${ }^{1}$
}

\section{Resumo}

O artigo se insere no âmbito dos estudos sobre políticas educacionais, notadamente sobre as políticas de avaliação da pós-graduação em Educação, intensificadas no Brasil, na década de 1990, com a reforma educacional de matriz neoliberal. Busca-se analisar os processos de interpretação e tradução da política pelos Programas de Pós-Graduação em Educação que, na avaliação do triênio 2010, emergiram do conceito 5 para 6, alcançando o patamar de excelência, equivalente ao dos centros internacionais de pesquisa na área. Trata-se de pesquisa documental, cujas fontes de análise são documentos produzidos:1) pela Coordenação de Aperfeiçoamento de Pessoal de Nível Superior -CAPES, vinculada ao Ministério da Educação e responsável pela regulação das políticas de pós-graduação no Brasil; 2) pelos Programas de pós-graduação e postados no sistema de coleta CAPES, nos anos que compuseram a avaliação trienal 2010 (2007-2009). Os documentos estão disponíveis no site da CAPES e são de acesso livre. O estudo tem como base teórico-metodológica, a teoria da interpretação/tradução da política no contexto da prática (Theory of policy enactment) proposta por Ball, Maguire e Braun. Os resultados indicam que a política de avaliação, mesmo que altamente delimitada e configurada por rígidos critérios e padrões internacionais não é simplesmente implementada -linear e acriticamente- no contexto da prática. Nos limites consentidos, nos variados contextos relacionais envolvidos, os atores produzem uma leitura ativa dos textos da política, que se transforma em objeto de recontextualização, reconfiguração e tradução.

\section{Palavras-chave}

Política educacional, política de avaliação, pós-graduação, «policy enactment», performatividade.

\section{Resumen}

El artículo aborda las políticas educativas, especialmente las políticas de evaluación de postgrado implementadas en la reforma educativa neoliberal de Brasil en los años noventa. El propósito es analizar los procesos de interpretación y traducción de la política dirigida a los programas de postgrado en educación que, en la evaluación del trienio 2010, emergieron del concepto 5 a 6 , alcanzando el nivel de excelencia, equivalente al de los centros de investigación internacional en el área. Se trata de una investigación documental, cuyas fuentes de análisis son documentos producidos por 1) la Coordinación de Perfeccionamiento de Personal de Nivel Superior -CAPES, vinculada al Ministerio de Educación y responsible de la regulación de las políticas de postgrado en Brasil; 2) los programas de postgrado y aplicados en el sistema CAPES, en los años que comprendieron la evaluación trienal 2010 (2007-2009). Los documentos están disponibles en la plataforma de CAPES y son de acceso libre. El estudio tiene como base teórico-empírica, la teoría de la interpretación-traducción de la política en el contexto de la práctica (Theory of policy enactment) propuesta por Stephen Ball, Maguire y Braun. Los resultados indican que la política de evaluación, incluso estando muy delimitada y configurada por criterios severos y modelos internacionales, no es simplemente implementada -de manera lineal y acrítica- en el contexto de la práctica. Dentro de los márgenes permitidos, en los variados contextos relacionales implicados, los actores producen una lectura activa de los textos de la política, que se transforma en un objeto de recontextualización, recofiguración y traducción.

\section{Palabras clave}

Política educative, política evaluadora, postgrado, «policy enactment», performatividad.

\footnotetext{
1 Universidade do Vale do Itajaí, Brasil, Regina Célia Linhares Hostins, reginalh@univali.br
} 


\begin{abstract}
The study discusses educational policies, especially postgraduate evaluation policies implemented in Brazil's neoliberal education reform in the 1990s. The aim is to analyze the interpretation and translation of Brazil's postgraduate education programmes' evaluation policy which, in the evaluation of the triennium 2010, emerged from the concept 5 to 6, reaching the level of excellence, equivalent to the international research centers in education. It is a documentary research, whose sources of analysis are documents produced: 1) by the Coordination of Improvement of Higher Education - CAPES, linked to the Ministry of Education and responsible for the regulation of postgraduate policies in Brazil; 2) by the postgraduate programmes and applied in the CAPES system, in the years of the triennial evaluation of 2010 (2007-2009). The study is based on the theory of 'policy enactments' proposed by Stephen Ball, Maguire and Brown. The results indicate that the evaluation policy, even if highly delimited by strict criteria and international standards, is not simply implemented - linearly and uncritically - in the context of practice. Within the limits allowed, in the relational contexts involved, the actors produce an active reading of the policy texts, which becomes an object of recontextualization, reconfiguration and translation.
\end{abstract}

Key words

Educational policy, evaluation policy, postgraduate education, policy enactment, performativity.

Recibido: 30-03-2017 Aceptado: 02-05-2017

\title{
1. Introdução
}

O ano de 1996 marcou a proposição de mudanças na política de avaliação da pós-graduação no Brasil, momento em que os ajustes neoliberais da reforma educacional atingiram seu ponto máximo. A Coordenação de Aperfeiçoamento de Pessoal de Nível Superior - CAPES, vinculada ao Ministério de Educação e responsável pela implantação dessa política no país, a partir dessa data, introduziu um «novo paradigma de referência», fortalecida pela necessidade de introduzir indicadores que expressassem os níveis de concorrência e de competitividade entre os programas. Nas palavras do ex-presidente da agência, Abílio Afonso Baeta Neves (Brasil, 2002:6), as mudanças na sistemática de avaliação fundamentavam-se no «reconhecimento claro de que a avaliação não discriminava mais a excelência», pois a maioria expressiva dos programas obteve conceitos A e B, tanto nas avaliações de 1994, como nas de 1996. Nesse sentido, a CAPES mudou para uma avaliação competitiva entre os programas, a partir de indicadores de excelência de qualidade, que a cada momento poderiam ser movidos para cima.

Sob a concepção dominante dos necessários ajustes neoliberais na «transformação das formas de estado» (Shaw, 1997:497) e na configuração das políticas, os quais envolviam a propagação epidêmica de privatizações, flexibilidade e avaliação, a reforma universitária foi implantada no Brasil e produziu mudanças radicais no ensino superior e na pós-graduação.

A Lei da Reforma Educacional (Lei das Diretrizes e Bases da Educação Nacional - LDBEN N 9394/1996) aprovada em 1996 e as regulamentações dela decorrentes, ampliaram as possibilidades de um arranjo particular de governança para tornar o sistema de ensino superior «mais acessível a uma estratégia de acumulação global» (Robertson et al., 2006:233).

Na pós-graduação, a reforma promoveu mudanças nos financiamentos das pesquisas, nas relações com o setor privado via mestrados de caráter profissional, na internacionalização e no controle da eficiência por meio do sistema de avaliação. 
Em face dessa reforma, a CAPES, a partir de 1998, realizou novas adequações na política de avaliação que passou a compreender as atividades de acompanhamento anual dos programas e a Avaliação Trienal propriamente dita, efetuada no ano subseqüente ao do fechamento do triênio, momento no qual era atribuída a nota resultante da avaliação. Inicia-se assim o processo de avaliação continuada da pós-graduação no Brasil.

Na década de 2000, definem-se as condições nas quais a política de pós-graduação deveria enquadrarse e os critérios de avaliação valorizados. «Entre as novidades ou alterações figuram a pós-graduação stricto-sensu de caráter profissional, o incentivo à cooperação internacional [...], ou ainda a vinculação dos resultados da avaliação à homologação do Conselho Técnico-Científico (CTC) da agência» (Brasil, 2002a:26).

Três estratégias foram relevantes na mudança de abordagem da política: 1) a avaliação continuada com o monitoramento anual dos Programas e emissão de conceito no ano após o fechamento do triênio; 2) a adoção de uma nova escala de avaliação com scores de 1 a 7 , sendo 1 e 2 para scores abaixo do requerido e 6 e 7 para performances de excelência; 3) a introdução de um conjunto de critérios internacionais para distinguir a excelência: alta qualidade e presença do corpo docente no exterior, pesquisa científica e produção intelectual.

O que se depreende dessas estratégias é que, na reforma de pós-graduação brasileira, na década de 1990, a política de avaliação enfatiza a competitividade, a performance e a performatividade ${ }^{2}$ das instituições, dos Programas, dos professores e estudantes, que passam a concorrer entre si em busca das melhores credenciais e do acesso aos financiamentos de suas pesquisas. Nesse caso, a competitividade posiciona os vencedores e os perdedores, os produtivos e os improdutivos, numa «luta em torno da visibilidade» (Ball, 2006:693).

Para acessar às informações e controlar os programas, a CAPES criou um Sistema computadorizado de dados, o qual é continuamente atualizado pelos Programas. O sistema desenvolveu um modo mais preciso de controle e exploração dos indicadores de produtividade e no provimento de informações quantitativas e qualitativas de monitoramento da produção intelectual de professores e alunos.

Paralelamente ao sistema de coleta de dados, a agência constituiu um sistema de avaliação entre pares, com a criação das Comissões de Avaliação por áreas - CA, as quais são compostas por professores/ pesquisadores de renome nas respectivas áreas de conhecimento, responsáveis por realizar as avaliações fundamentados nos critérios estabelecidos. As CA avaliam os Programas e submetem seus pareceres à homologação do Conselho Técnico-Científico (CTC) da agência.

Essa complexa infraestrutura de dados e de envolvimento dos pesquisadores como sujeitos e objetos da avaliação, associada às medidas em escalas e aos critérios de comparabilidade, com base em critérios internacionalizados definem o que Ozga e Lingard (2007) denominam de «política de número». Essa se espraia para todos os estados-nação, produzem efeitos nas políticas nacionais e transformam as relações entre pesquisadores, professores, estudantes e instituições.

O artigo discute performance e performatividade na política de avaliação da pós-graduação no Brasil, tendo como foco de análise os discursos produzidos, tanto pela Coordenação da Área de Educação (CA-

2 Stephen Ball emprega o conceito de performatividade como «uma tecnología, uma cultura e um modo de regulação que emprega julgamentos, comparações e exibições como meios de incentivo, controle, disputas e mudança» (Ball, 2003:216). 
ED) na orientação, acompanhamento e avaliação da pós-graduação, como pelos Programas avaliados como de excelência e padrão internacional, nos anos que compuseram a avaliação trienal do ano base 2010 (2007-2009), notadamente os que emergiram do conceito 5 para o 6, no triênio.

A escolha do período em foco -2007 a 2010 - não foi aleatória. Neste intervalo de tempo, consolidase o processo de avaliação continuada da pós-graduação, após um período de reformulações e sucessivas adaptações da sistemática na década de 1990.

Na avaliação do primeiro triênio (1998-2000), após implantação do novo modelo avaliativo, o processo passou por ajustes, discussões, sérios embates e negociações entre as Comissões de Avaliação por Áreas, o Conselho Técnico-Científico - CTC da agência e os programas de Pós-Graduação. Somente no triênio iniciado em 2001 esse processo se estruturou no formato como se apresenta nos dias de hoje, com algumas alterações qualitativas nos últimos três anos.

Tendo como sustentação a abordagem teórico-metodológica de Ball et al., (2012), parte-se do pressuposto de que as políticas são interpretadas e traduzidas de diferentes e variadas formas para contextos específicos. «Assim, o material, o estrutural e o relacional precisam ser incorporados na análise de políticas para fazer o melhor sentido na colocação da política em ação no nível institucional» (Ball et al., 2012: 21). Para os autores, nos limites consentidos, nos variados contextos materiais e relacionais envolvidos, os atores produzem uma leitura ativa dos textos da política, que se transforma em objeto de recontextualização, interpretação e tradução.

A teoria da interpretação/tradução da política no contexto da prática (Theory of policy enactment) tem sido discutida por Stephen Ball et al. (2012) e empregada como recurso teórico-metodológico na análise de políticas. Para eles a interpretação é uma leitura inicial, com o objetivo de aproximar-se do sentido da política. Trata-se de uma leitura política e substantiva vinculada à linguagem da política. A tradução por sua vez vincula-se à compreensão do texto dentro dos limites da ação no quais ocorre um processo de re-representação, reordenação e refundamentação que se processam por meio de várias práticas materiais e discursivas (Ball et al., 2012).

Tendo por referencial a abordagem teórico-analítica apresentada, no estudo aprofundam-se as discussões e análises no campo preciso da política de avaliação da pós-graduação e, a partir desse locus particular, indaga-se: como os programas de Pós-Graduação em Educação (que emergiram da nota 5 para a 6 no triênio avaliado) interpretam e traduzem as múltiplas exigências da política de avaliação da Pós-Graduação dentro dos recursos a eles disponibilizados? Como isso se revela na construção dos seus textos nos relatórios de avaliação?

Essas questões norteiam a análise documental e o debate sobre a tradução da política de avaliação da pós-graduação no Brasil pelos principais atores da política, ou seja, os Programas avaliados.

\section{Contribuições de Stephen Ball para análise das políticas educacionais}

O método teórico-analítico desenvolvido por Stephen Ball e colaboradores destaca a «natureza complexa e controversa da política educacional, enfatiza os processos micropolíticos e a ação dos profissionais que lidam com as políticas no nível local e indica a necessidade de se articularem os processos macro e micro na análise de políticas educacionais» (Mainardes, 2006:49).

A teoria da interpretação/tradução da política no contexto da prática (Theory Of Policy Enactment), foi desenvolvida, mais recentemente, por Ball, Maguire e Braun (publicada no livro: How schools do policy: policy 
enactments in secondary schools, 2012), a partir de uma pesquisa realizada em escolas secundárias na Inglaterra e financiada pelo Conselho de Pesquisa Social (ESRC) intitulada: Policy enactments in the secondary school, desenvolvida entre outubro de 2008 a abril de 2011.

«Enactments» constituem respostas em curso à política, às vezes durável, às vezes frágil, nas diversas redes e cadeias de relações, mas essa resposta não é direta nem reproduz linearmente as diretrizes da política. É na interação e inter-relação entre diversos atores, textos, conversas, tecnologias e objetos (artefatos) que a política é interpretada, traduzida, reconstruída e refeita em diferentes, mas similares caminhos (Ball et al., 2012).

Para os autores, a interpretação é apenas uma leitura inicial, com o objetivo de aproximar-se do sentido da política. A tradução, por sua vez, vincula-se à compreensão do texto dentro dos limites da ação, no quais ocorre um processo de re-representação, reordenação que se processam por meio de várias práticas materiais e discursivas.

O aprofundamento de abordagens dessa natureza assume um papel significativo no campo de pesquisa em políticas educacionais, considerado relativamente novo no Brasil e «ainda não consolidado em termos de referenciais analíticos consistentes, e que, de resto, sofre as indefinições resultantes da crise de paradigmas que afeta as ciências sociais e humanas na contemporaneidade» (Azevedo e Aguiar, 1999:43).

Em uma perspectiva que se distancia de posições binárias, Ball (2011:44) defende uma posição epistemologicamente diferente e declara-se interessado em questões sobre «a ontologia da política», ou sobre a «forma como nós tornamos as políticas encarnadas». O autor busca romper com a ideia de que as políticas são feitas para as pessoas e estas as implementam. As políticas são antes objetos de alguma forma de tradução ou de leitura ativa; um tipo de «ação social criativa». Em seus processos e atos, é necessário capturar não os efeitos sobre coletividades sociais abstratas, mas antes a interação complexa de identidades, interesses, coalizões e conflitos (Ball, 2011).

Braun, Ball e Maguire (2011) exploram as formas com a qual os professores e gestores interpretam, adaptam ou transformam as políticas por meio da lente de seus valores, conhecimentos pré-existentes e práticas. Eles analisam o papel de diferentes tipos de atores políticos (policy actors) e identificam diferentes tipos de políticas, temas da política e as formas com que a política fala aos professores. Os autores consideram que enquanto muita atenção tem sido dada para avaliar quão bem as políticas são implementadas, ou seja, o quão bem elas são realizadas na prática, menos atenção tem sido dada para a compreensão e documentação das formas com as quais as escolas realmente lidam com o múltiplo, e às vezes, com as demandas opacas e contraditórias de diferentes «tipos» de política.

Em face desses pressupostos, no artigo ora apresentado, busca-se evidenciar as interpretações e traduções da política pelos atores políticos envolvidos de forma direta na avaliação da pós-graduação, seja como avaliadores ou como avaliados.

\section{Procedimentos Metodológicos}

A pesquisa, de caráter qualitativo, foi conduzida por meio de pesquisa documental cujas fontes foram coligidas no portal da CAPES (WWW.capes.gov.br) no menu Avaliação.

\subsection{População e delimitação do estudo}

Foram objetos de estudo os Programas de Pós-Graduação em Educação que no triênio 2010 da ava- 
liação continuada da CAPES emergiram da nota 5 para a 6 e, a partir de então, passaram à condição de Programas internacionais de excelência, com nível de desempenho altamente diferenciado em relação aos demais programas da área.

Considerou-se que os Programas nessa condição poderiam melhor expressar o movimento de interpretação e tradução das políticas no contexto da prática. Afinal, para garantir a passagem da nota 5 para 6 deve haver um grande investimento do Programa e, por consequência, de todos os atores envolvidos, para alcançar os critérios de alto desempenho requeridos como:

1. Conceito Muito Bom nos cinco quesitos avaliados;

2. Média de produção bibliográfica por docente permanente de 21 pontos, ou seja, cerca de $20 \%$ acima da necessária para conceito Muito Bom (o equivalente em pontos a 1,5 artigo em periódico internacional A por docente/ano)

3. Número de titulados de doutorado correspondente a, no mínimo, $80 \%$ do total de docentes permanentes no decorrer de todo triênio.

Os Programas que atingem esses requisitos mínimos sofrem uma segunda avaliação, realizada por uma subcomissão, de acordo com os critérios definidos CTC sendo eles:

Item 1: Nível de Qualificação, de produção e de desempenho equivalente ao dos centros internacionais de excelência na formação de recursos humanos.

Item 2: Consolidação e liderança nacional do Programa como formador de recursos humanos para a pesquisa e a pós -graduação.

Item 3: Inserção e impacto regional e nacional do Programa considerando indicadores de integração e solidariedade com outros programas com vistas ao aprimoramento do sistema de pós-graduação e de visibilidade de sua atuação.

Considerando os resultados da avaliação dos triênios dos anos base 2007 e 2010 participaram da amostra quatro (4) programas: um pertencente a uma universidade confessional e três pertencentes a universidades públicas (uma estadual e duas federais), a saber: Pontifícia Universidade Católica do Rio Grande Do Sul - PUCRS, Universidade Federal Fluminense - UFF, Universidade de São Paulo - USP e Universidade Federal de São Carlos - UFSCar.

\subsubsection{Perfil dos Programas estudados}

Programa de Pós-Graduação em Educação da Pontifícia Universidade Católica do Rio Grande Do Sul-PUCRS: O Programa faz parte da Faculdade de Educação e é integrado pelo Curso de Mestrado (que teve início em 1972 e foi credenciado em 1976) e o Curso de Doutorado (que foi criado em 1988 e credenciado em 1995). À época, possuía corpo docente formado por 14 professores.

Programa de Pós-Graduação em Educação da Universidade Federal Fluminense - UFF: O Programa mantém o Mestrado Acadêmico, desde 1971, e o Doutorado, criado em 1995. O corpo docente do Programa, em 2009, constituiu-se de 33 professores permanentes e 10 professores colaboradores.

Programa de Pós-Graduação em Educação da Universidade de São Paulo - USP: Criado em 1971, o Programa contou, no ano de 2009, com 96 docentes, dos quais 77 do grupo de docentes permanentes, 14 colaboradores e 5 colaboradores aposentados que estavam se desligando do programa. 
Programa de Pós-Graduação em Educação Especial da Universidade Federal de São Carlos - UFSCar. o Programa completou em 2009, 32 anos de funcionamento do curso de mestrado e dez anos do curso de doutorado, e neste período consolidou um centro reconhecido de pesquisas no país e no exterior, com um corpo docente constituídos por 29 docentes.

\subsection{Procedimentos de coleta e análise de dados}

Foram selecionados os documentos: 1) Cadernos de Indicadores: gerados a partir dos dados preenchidos pelos Programas no processo de avaliação continuada e 2) Documentos de Áreas, Relatórios de Avaliação e Resultados da Avaliação de Programas gerados pela CAPES e preenchidos pela Comissão de Avaliação da Área de Educação (CA-Ed).

Os procedimentos de aproximação e análise documental foram assim sistematizados:

1. Leitura prévia dos documentos cadastrados no Coleta CAPES pelos Programas selecionados e divulgados nos Cadernos de Indicadores buscando indícios reveladores das semelhanças e diferenças entre um texto e outro, mediante anotações prévias das regularidades e das diferenças, serviram de elementos para uma primeira classificação ou descrição das evidências mais significativas.

2. Tabulação dos dados em planilha eletrônica Excel.

3. Análise da planilha no sentido de «rastrear a conexão íntima» dos dados. Nessa etapa foram destacadas as palavras-chave dos textos e as categorias de menor e maior complexidade, por meio da Análise de conteúdo.

4. Análise de correlação entre os Programas alternando leituras verticais e horizontais das categorias por meio de tabela dinâmica.

5. Sistematização e aprofundamento das análises estabelecendo correlações com o referencial teórico estudado e outros autores e obras evidenciados na análise da empiria.

Documentos coligidos

BRASIL. CAPES. Relatório de avaliação 2007-2009. Trienal 2010. Comissão de área da Educação.

BRASIL. CAPES. Relatório de avaliação 2004-2006. Trienal 2007. Comissão de área da Educação.

BRASIL. CAPES. Comissão de Área da Educação. Ficha de Avaliação do Programa de PósGraduação PUC/RS - Pontifícia Universidade Católica do Rio Grande do Sul. Ano base 2010 (2007-2009).

BRASIL. CAPES. Caderno de Indicadores: proposta do programa. Pontifícia Universidade Católica do Rio Grande do Sul. Ano base 2010 (2007-2009).

BRASIL. CAPES. Comissão de Área da Educação. Ficha de Avaliação do Programa de Pós-Graduação da UFF - Universidade Federal Fluminense. Ano base 2010 (2007-2009).

BRASIL. CAPES. Caderno de Indicadores: proposta do programa. UFF - Universidade Federal Fluminense. Ano base 2010 (2007-2009).

BRASIL. CAPES. Comissão de Área da Educação. Ficha de Avaliação do Programa de Pós-Graduação da UFSCAR - Universidade Federal de São Carlos. Ano base 2010 (2007-2009). 
BRASIL. CAPES. Caderno de Indicadores: proposta do programa. UFSCAR - Universidade Federal de São Carlos. Ano base 2010 (2007-2009).

BRASIL. CAPES. Comissão de Área da Educação. Ficha de Avaliação do Programa de Pós-Graduação da USP - Universidade de São Paulo. Ano base 2010 (2007-2009).

BRASIL. CAPES. Caderno de Indicadores: proposta do programa. USP - Universidade de São Paulo. Ano base 2010 (2007-2009).

WEBCAPES. Disponível em http://www. capes.gov.br.

\section{A tradução da política pelos Programas do Pós-Graduação: construção dos discur- sos em torno do critério de organicidade}

A análise iniciou com o estudo do documento: Propostas dos Programas (PO), -de cada um dos anos avaliados- estabelecendo correlações com a ficha de avaliação do Programa pela CA-Ed, no sentido de apreender quais mudanças, incorporações, alterações e adaptações foram sendo processadas na trajetória e como os programas foram interpretando e traduzindo os elementos da política e construindo seus discursos em resposta a ela.

A análise, sustentada na teoria de Ball (2011) e Ball et al., (2012), parte do pressuposto de que os Programas se consolidam com base na informação que constroem e transmitem sobre si. Na construção do discurso, estes se articulam num jogo representacional de luta por visibilidade e de intensificação da produção e da qualidade.

Esse exercício evidenciou uma riqueza de dados e um expressivo potencial de discussão da Política de Avaliação, desde a perspectiva dos Programas. Para os propósitos deste artigo e considerando os limites do texto, buscar-se-á analisar como a categoria organicidade priorizada no instrumento de avaliação da Comissão de Área (CA-Ed) e central no processo de avaliação, a partir desse período, foi traduzida e se materializou na produção dos discursos dos Programas ${ }^{3}$.

Essa categoria avaliava a coerência, consistência e abrangência entre área(s) de concentração, linhas e projetos de pesquisa, publicações de docentes, estrutura curricular, dissertações e teses dos Programas, de modo delimitar de maneira clara o objeto de especialidade da produção do conhecimento e da formação realizada no Programa e por ele oferecida (Brasil, CA-Ed, 2007).

Buscou-se então identificar o diálogo que se estabeleceu entre, de um lado, o avaliador com os quesitos, as apreciações e as recomendações em torno da organicidade e de outro, o avaliado com as justificativas, as descrições minuciosas e as representações performáticas.

Nesse suposto diálogo há um desenho de expectativas e um movimento intenso de descrições, definições, estratégias e representações na tentativa de correspondê-las. Instala-se assim, o que Ball (2010:39) define como novo modo de regulação em que o que está à frente não é mais a organização do poder dentro de formas de tempo-espaço definitivos. É a base de dados, a reunião de avaliação, a avaliação anual, a elaboração de relatórios e os formulários, as inspeções, a avaliação dos pares que estão à frente. «A questão não é sobre a possível certeza de ser sempre vigiado, como ocorre no panóptico. Se trata, ao contrário, da incerteza e da instabilidade de ser julgado de diferentes maneiras, por diferentes meios e diferentes

3 Utiliza-se a denominação numérica para identificação do Programas: P1, P2, P3 e P4, definida de forma aleatória para evitar o uso nominal. 
agentes». O que se produz então é um «estado de permanente e consciente visibilidade» (Ball, 2010:40).

Tão complexa é essa questão no interior dos programas que na avaliação do triênio 2007, a CA-Ed identificou três tendências em relação à organicidade de linhas de pesquisa, nos programas avaliados:

«1) aqueles que apresentaram linhas de pesquisa em uma abordagem que as aproximou do conceito tradicional (tendência menos evidente dentre as três); 2) programas que indicaram linhas muito abrangentes, aparentemente criadas de maneira indutiva para agregar o conjunto de projetos existentes; e, finalmente, 3) programas que mencionaram linhas abrangentes que, em verdade, estavam mais próximas do conceito de área de concentração, visto que envolviam não apenas projetos de pesquisa, mas também disciplinas e outras atividades especificas. A opscão por uma grande abrangência facilita a inclusão de projetos de pesquisa das mais variadas temáticas, mas tende a obscurecer a organicidade do programa». (Brasil, CA-Ed, 2007:25)4.

Vale destacar que, no triênio anterior, o de 2004, a CA-Ed alerta, especificamente no relatório de avaliação de um dos Programas, o P1, para a necessidade de manter uma coerência entre as linhas e projetos, afinal:

«[...] problemas destacados na avaliação anterior ainda persistem e, em alguns casos, se agravaram. [...] Ainda fica nebuloso o eixo conceitual que articula as 10 linhas de pesquisa do Programa que, no seu conjunto, abordam grande parte da área da Educação. Da mesma forma, não se percebe com clareza a lógica que orientou a distribuição de alguns dos projetos entre as mesmas». (Brasil, CA-Ed, P1, 2004:1, grifo nosso).

Essa questão parece se constituir em ponto de embate entre o Programa e a Comissão de Área. Nos triênios subsequentes, o Programa explicita seu posicionamento em relação a organicidade:

«A aparente diversidade característica das linhas de pesquisa, que refletem múltiplas alternativas disciplinares e epistemológicas, ganha maior organicidade ao se compreender que, as mesmas, abrigam uma concepção da educação como fenômeno multireferencial, que exige estratégias de pesquisas advindas de áreas diferentes. Para além disso, o fato é que as disciplinas oferecidas se ancoram, também elas, em perspectivas teórico-metodológicas e nos estudos e pesquisas desenvolvidos pelos professores». (Brasil, P1, 2009:3, grifo nosso).

Se para a Comissão de avaliação a organicidade do Programa avaliado parecia nebulosa, para P1, esta, se ancorava na concepção da multireferencialidade manifesta nas perspectivas teórico-metodológicas e nos estudos e pesquisas desenvolvidos pelos professores. Nesse embate, observa-se um Programa que constrói argumentos para responder, a seu modo, aos critérios da política criando um conceito capaz de manter como orgânica a aparente diversidade de suas linhas de pesquisa.

Se, do ponto de vista da política esse critério busca assegurar a unidade, no contexto da prática, no interior dos Programas, ele assume outras dimensões, por que diretamente vinculado às experiências e trajetórias acadêmicas do corpo docente e do Programa.

Para reafirmar sua concepção em torno da organicidade como «multireferencialidade», P1 descreve as estratégias adotadas no interior do Programa: os Encontros de Pesquisa das Linhas e a nucleação dos

4 Daqui para frente, serão apresentados os recortes da empiria em itálico e as referências destacando: fonte do documento (Brasil), quem produziu o documento: CAEd, o Programa que está sendo avaliado P1, P2, P3 ou P4, o ano de produção do documento e a página. Quando se tratar de documento produzido pelo Programa a referência será: Fonte (Brasil), Programa (P1, P2, P3 ou P4), ano e página. 
professores por grupos de pesquisa:

«Tais encontros agruparam tanto os alunos e professores a elas filiados, como outros interessados. [...]. A realização dos Encontros oportuniza, assim, significativa mediação concreta entre as disciplinas e o desenvolvimento das pesquisas, pois permitem uma saudável circulação e intercâmbio de questões, opções temático-metodológicas e soluções práticas na condução dos trabalhos dos alunos. Isso também ocorre em atividades especificas de muitos dos 42 grupos de pesquisa cadastrados no diretório de grupos do $\mathrm{CNPq}$ (grupos coordenados por um mesmo docente estão sendo unificados, o que poderá representar uma redução desse número nos próximos anos). Ao mesmo tempo, está se desenvolvendo um processo de nucleação de todos os professores em grupos de pesquisa». (Brasil, P1, 2009:3).

Nas estratégias adotadas, evidencia-se um modo particular de responder às exigências da política e uma forma peculiar de traduzir suas diretrizes. Um misto de capitulação e resistência, como sugere Ball (2010). Significa dizer que o Programa resiste mantendo sua concepção ampliada de organicidade, mas capitula ao intensificar as formas de controle dos grupos existentes com a estruturação colegiada de discussão, o acompanhamento e a autoregulação do funcionamento das Linhas de Pesquisa e disciplinas viabilizadas, por exemplo, pelos Encontros de Pesquisa.

Ball define isso como um jogo particular de regulação ou governamentalidade, as quais têm, simultaneamente, uma dimensão social e interpessoal:

"Elas são subentendidas dentro de um complexo institucional, de equipe, de grupo e de relações comunitárias - a comunidade acadêmica, a escola, os departamentos, a universidade, por exemplo. Nós nos embasamos na avaliação dos pares, nós redigimos as prestações de conta, nós atribuímos graus aos outros departamentos, nós repreendemos nossos colegas por sua pobre produtividade, nós planejamos, pomos a funcionar e alimentamos os procedimentos departamentais e institucionais para monitorar e melhorar os resultados». (Ball, 2010:41).

Trata-se, pois, de formas de resposta/resistência e acomodação à performatividade.

O P4 também procura definir um conceito para expressar sua perspectiva de organicidade. Trata-se do conceito de campo de confluência:

"[...] o Programa passou a organizar suas atividades de pesquisa e de docência em Campos de Confluência. A adoção dos Campos de Confluência decorreu de um amplo debate interno e também das discussões nacionais que marcaram a década de 1980, no campo da pós-graduação em educação. Sua concepção entende a educação como um processo e uma prática constituida e constituinte das relações sociais. No plano epistemológico e teórico, a organizaçãa do Programa em Campos de Confluência tem como objeto a construção de conbecimentos, buscando orientar a ação politica, as práticas educativas institucionalizadas em formas específicas de ação educativa e as práticas que se forjam nos movimentos, lutas sociais e outros espaços-tempos educativos na cidade e no campo». (Brasil, P4, 2009:3, grifo nosso).

Essa concepção contribuiu para a avaliação do quesito organicidade pela Comissão que afirma ter sido possível, a partir dessa estratégia adotada pelo Programa, construir uma representação discursiva da sua proposta.

«O Programa organiza-se em seis Campos de Confluência, desdobrados em Linhas de Pesquisa. As linhas de pesquisa e os projetos em andamento são consistentes, abrangentes e atualizados. Há 
relação dos projetos com as linhas de pesquisa em que se inserem e obteve conceito Muito Bom. A descrição da estrutura curricular foi detalhada, permitindo observar a organicidade entre as linhas, os projetos de pesquisa, a estrutura curricular e as temáticas das dissertações. [...]. Considerando-se tais análises, o Programa foi conceito Muito Bom quanto à coerência, consistência e abrangência da estrutura curricular neste triênio». (Brasil, CA-Ed, P4, 2010:1, grifo nosso).

O P2, mesmo tendo sido avaliado com o conceito muito bom neste quesito nos triênios avaliados, descreve no seu relatório de 2009, que iniciou um intenso movimento de transformação de suas estruturas e formas de organização ao levar em conta as exigências internas e externas de avaliação:

«O Programa [...], neste triênio, passou por um complexo processo de modificações em sua estrutura e organização [...]. Isso ocorreu, em parte, devido ao conjunto de exigências institucionais advindas tanto da nossa Universidade quanto das alterações processadas no âmbito do Sistema Nacional de Pós-Graduação e estabelecidas pela CAPES. Por outro lado, devido à própria necessidade de atualização, renovação e mudança, fruto dos sucessivos processos de auto-avaliação que temos levado a efeito. Nesse sentido, trata-se de mudanças que realizamos no currículo, nas Linhas de Pesquisa, no quadro docente, nos Grupos de Pesquisa e em algumas sistemáticas e normativas de funcionamento do Programa. Vale considerar que essas modificações vêm sendo implementadas progressivamente a partir dos últimos anos, conferindo a elas mais ênfase nos anos de 2008 e 2009. [...]. Ao longo deste Relatório, portanto, serão apresentadas e descritas diferentes iniciativas de modificação, buscando-se assegurar uma visão articulada da organicidade do Programa, tanto em seu âmbito mais particular quanto no âmbito institucional local, regional, nacional e internacionali. (Brasil, P2, 2009: 2, grifo nosso).

O uso de táticas discursivas e de estratégias diferenciadas na gestão são algumas das formas de tradução da política pelos Programas que são exigidos a construir uma variedade de descrições textuais de si mesmos. Ball (2010) considera que em dois sentidos, o simbolismo é tão importante quanto a substância. Primeiro, eles simbolizam e representam o consenso incorporado da instituição, evidenciando atividades em torno de um conjunto de prioridades acordadas. Segundo, eles demonstram «o padrão do esforço compartilhado que desloca ou subsume diferenças, desacordos e divergências de valor». (Ball, 2010:48).

No caso de P2, simbolismo e substância se encontram na demonstração do esforço da instituição, em definir diferentes iniciativas de modificação, buscando-se assegurar uma visão articulada da organicidade do Programa.

As iniciativas adotadas repercutem positivamente na comissão que, por sua vez, reconhece o trabalho do Programa:

«A relação dos projetos com as linhas de pesquisa em que se inserem é conceito Muito Bom. A descrição da estrutura curricular foi detalhada, permitindo observar organicidade entre as linhas, os projetos de pesquisa, a estrutura curricular e as temáticas das dissertações e teses. O conjunto das disciplinas e suas respectivas bibliografias é atual e está em consonância com o corpo docente. Considerando-se tais análises, o Programa foi Muito Bom quanto à coerência, consistência a abrangência da estrutura curricular neste triênio». (Brasil, CA-Ed, P2, 2010:1).

Nesse discurso, uma demonstração do modo como a política pode tornar os Programas mais responsivos. E nesse sentido, os textos escritos têm especial papel por concederem espaço à performatividade e possibilitarem o uso do significado correto, ou do significado esperado pela política.

Nesta mesma perspectiva, o P.3 anuncia e reafirma como parte de sua identidade a busca da coerência 
na configuração de sua proposta. O documento do Programa destaca que este se consolidou, a partir de dois fatores que contribuíram para tal: a especificidade do Programa e os resultados do sistema de avaliação da CAPES.

O Programa considera que a exigência da Capes em torno da delimitação das áreas de concentração e da organicidade com as linhas de pesquisa contribuiu para a valorização da sua especificidade:

«Se antes todos os programas eram genericamente denominados como sendo de "educação" na atualidade os programas tendem a ser mais delimitados e, consequentemente cresce o número de programas especificos. Neste contexto a especificidade, que já é tradicional do programa desde sua criação se torna um ponto a favor para sua identidade e organicidade, e aliado ao fato dele permanecer sendo o único programa específico [...], 32 anos após sua criação, potencializa sua contribuição para a pósgraduação na área de Educação em nosso país». (Brasil, P3, 2009:3).

Na avaliação da comissão essa concepção e estrutura adotada pelo Programa é coerente e contribuiu para o alcance do conceito Muito Bom:

"A descrição da estrutura curricular foi detalhada, permitindo observar organicidade entre as linhas, os projetos de pesquisa, a estrutura curricular e as temáticas das dissertaçoes e teses. O conjunto das disciplinas e suas respectivas bibliografias é atual e está em consonância com o corpo docente. Considerando-se tais análises, o Programa obteve conceito Muito Bom quanto à coerência, consistência e abrangência da estrutura curricular neste triênio». (Brasil, CA-Ed, P3, 2010:1).

«Multireferencialidade educacional», «campo de convergência», «visão articulada», «especificidade/ identidade» são importantes táticas discursivas utilizadas para demonstrar a conexão com a política, mas também para expressar um modo específico de pensar, de agir e de criar conceitos e simbolismos por parte dos Programas. Um paradoxo, um misto de adequação e resistência. «Elas significam, encapsulando ou representando um valor, a qualidade ou a valia de um indivíduo ou de uma organização dentro de um campo de julgamento» (Ball, 2010:38). Elas atuam como medidas de produtividade e de resultados, como formas de apresentação da qualidade, mas também revelam construções próprias, resoluções traduzidas, reconstruídas em diferentes, mas similares caminhos.

Está se tratando aqui do que Ball, Maguire e Braun (2012) chamam de «enactments». Ou seja, está se falando das respostas em curso à política, às vezes durável, às vezes frágil, as vezes resistentes e sempre configuradas nas diversas redes e cadeias de relações.

\section{Considerações finais}

O percurso e o exercício de análise empreendido nesse estudo permitiram discutir importantes indicadores, princípios e tendências que delineiam a política de avaliação da pós-graduação e sua tradução nos Programas de Pós-Graduação em Educação, que na avaliação do triênio 2010 obtiveram avanços nos seus conceitos, isto é, emergiram da nota 5 para a nota 6 , alcançando nesse triênio a avaliação de desempenho equivalente ao dos centros internacionais de excelência na área.

A avaliação da pós-graduação brasileira tem sido motivo de debate, o qual ganhou força, no final da década de 1990 quando se estabeleceram critérios e padrões de avaliação em caráter continuado e quando se definiu a pesquisa como atividade central e precípua da pós-graduação brasileira. O momento representou uma mudança de paradigma especialmente porque estabeleceu índices comparativos e níveis 
de qualidade traduzidos em conceitos/notas, que implicaram em alterações não somente nos objetivos e processos educativos, como também interferiram fortemente na reengenharia de valores (Ball; Cribb, 2005) das instituições e programas de pós-graduação, com ênfase nos resultados, na definição de novas obrigações e na valorização de iniciativas empreendedoras de alunos, professores e gestores.

A pesquisa se inseriu nesse contexto de mudanças de paradigma, com o propósito de analisar e compreender o complexo processo de interpretação e tradução das políticas, levando em conta as variações de contextos, de recursos e de participação e leitura ativa dos atores do processo.

A análise de dados me permitiu observar que a política de avaliação, mesmo que altamente delimitada e configurada por rígidos critérios e padrões internacionais não é simplesmente implementada -linear e acriticamente- no contexto da prática. Nos limites consentidos, nos variados contextos materiais e relacionais envolvidos, os atores produzem uma leitura ativa dos textos da política, que se transforma em objeto de recontextualização, interpretação e tradução.

Do ponto de vista geral pode-se afirmar que os discursos adotados e as ações efetivadas no interior dos Programas evidenciam tanto um movimento em busca da organicidade e da reafirmação de suas identidades, como de fabricação de discursos para responder à política.

No sentido amplo de pesquisa, as dimensões analisadas -nos Documentos das Comissões de Área, e nos documentos da Proposta dos Programas- revelam respostas e experiências ativamente vivenciadas no contexto da prática, redefinidas por táticas discursivas e traduzidas no interior dos Programas.

Neste sentido, ganhou expressão no estudo a categoria de organicidade (coerência e coesão), dada sua regularidade, relevância e ênfase no teor dos documentos e da política como um todo. Observou-se que essa categoria foi central no processo de avaliação e, particularmente, demonstrou o modo como os atores da política foram moldando seu significado, em um verdadeiro embate de resistência e capitulação aos critérios e diretrizes da política.

Táticas discursivas foram utilizadas para demonstrar a conexão com a política, mas também para expressar um modo específico de pensar, de agir e de criar conceitos e simbolismos por parte dos Programas. Um paradoxo, um misto de adequação e resistência. Essas táticas atuam como medidas de produtividade e de resultados, como formas de apresentação da qualidade, mas também revelam construções próprias, resoluções traduzidas, reconstruídas em diferentes, mas similares caminhos.

\section{Referências bibliográficas}

Azevedo, J.M.L.; Aguiar, M.A. (1999): "Políticas de educação: concepções e programas" in L. C. Wittmann; R. V. Gracindo (coords.): O estado da arte em política e gestão da educação no Brasil: 1991 a 1997. Brasília: INEP.

Ball, Stephen J. (2003): “The Teacher's Soul and the Terrors of Performativity”. Journal of Education Policy, $18(2), 215-228$.

Ball, Stephen J. (2006): "Performativities and Fabrications in the Education Economy: Towards the Performative Society" in: Lauder H. et al., (orgs): Education, Globalization and Social Change. Oxford: Oxford UniversityPress.

Ball, Stephen J. (2010): "Performatividades e fabricações na economia educacional: rumo a uma sociedade performativa". Educação \& Realidade, 35 (2), 37-55. 
Ball, Stephen J. (2011): "Sociologias das políticas educacionais e pesquisa crítico-social: uma revisão pessoal das políticas educacionais e da pesquisa em política educacional” in Stephen J. Ball; J. Mainardes. Políticas Educacionais: questões e dilemas. São Paulo: Cortez.

Ball Stephen J.; Cribb, A. (2005): “Towards an ethical audit of the privatisation of education”. British Journal of Educational Studies, 53, (2), 115-28.

Ball, Stephen J.; Maguire, Meg; Braun, Annette (2012). How schools do policy: policy enactments in secondary schools. London: Routledge.

Brasil. Capes (2002). 50 anos. Brasilia: CAPES/CPDOC/FGV.

Brasil. Capes (2002a). Infocapes: Boletim Informativo da CAPES. v. 10, N. 4, Brasília, CAPES/MEC, out - dez.

Braun, Annette; Ball, Stephen J.; Maguire, Meg (2011): "Policy enactments in schools introduction: towards a toolbox for theory and research". Discourse: Studies in the CulturalPolitics of Education, 32 (4), 581-583.

Mainardes, Jefferson (2006): "Abordagem do ciclo de políticas: uma contribuição para a análise de políticas educacionais". Educ. Soc., 27, (94), 47-69.

Ozga, Jenny; B. Lingard. (2007): "Globalisation, Education Policy and Politics.” in B. Lingard; Jenny Ozga. (eds.): The-Routledge Falmer Reader in Education Policy and Politics. London: Routledge Falmer.

Robertson, S. L.; Bonal, X; Dale, R. (2006): "GATS and the Education Service Industry: The Politics of Scale and Global Reterritorialization” in H. Lauder et al., (eds.): Education, Globalization and Social Change. Oxford: Oxford University Press.

Shaw, Martin (1997): "The State of Globalization: towards a theory of state transformation”. Review of International Political Economy, 4(3), 497-513.

\section{Nota biográfica}

Regina Célia Linhares Hostins es Doctora en Ciencias de la Educación por la Universidade Federal de Santa Catarina (2006), Brasil. Realizó un posdoctorado en 2013, en el Institute of Education, University of London, como colaboradora del Dr. Stephen Ball, en el campo de la Sociología de la Educación, desarrollando estudios sobre aspectos teórico-metodológicos en la investigación de políticas educativas. Es profesora e investigadora del Programa de Pós-Graduação em Educação en la Universidade do Vale do Itajaí y coordina el grupo de investigación «Observatório de Políticas Educacionais». Participa en la red de investigadores del Observatório Nacional de Educação Especial, un consorcio compuesto por 22 universidades brasileñas. 